\title{
Laparoscopic Abdominoperineal Resection for Low Rectal Cancer at National Cancer Hospital of Vietnam
}

\author{
Binh V. Pham1, Anh T. Pham², Su Bin Kim³, Tran Van Thuan², Nguyen Tien Quang² \\ ${ }^{1}$ Department of Surgical Oncology, National Cancer Hospital of Vietnam, Hanoi, Vietnam \\ ${ }^{2}$ Department of Medical Oncology, National Cancer Hospital of Vietnam, Hanoi, Vietnam \\ ${ }^{3}$ Miller School of Medicine, University of Miami, Jackson Memorial Hospital, Miami, FL, USA \\ Email: phamtuananh@hmu.edu.vn
}

How to cite this paper: Pham, B.V., Pham, A.T., Kim, S.B., Van Thuan, T. and Quang, N.T. (2017) Laparoscopic Abdominoperineal Resection for Low Rectal Cancer at National Cancer Hospital of Vietnam. Open Access Library Journal, 4: e4020. https://doi.org/10.4236/oalib.1104020

Received: October 11, 2017

Accepted: November 27, 2017

Published: November 30, 2017

Copyright $\odot 2017$ by authors and Open Access Library Inc.

This work is licensed under the Creative Commons Attribution International License (CC BY 4.0).

http://creativecommons.org/licenses/by/4.0/

\begin{abstract}
Introduction: Results of laparoscopic colectomies from developing nations are reported rarely. We report our results of laparoscopic abdominoperineal resection (LAPR) for low rectal cancer at K Hospital (National Cancer Hospital of Vietnam). Materials \& Methods: From January 2012 to December 2015, a total of 135 patients who were diagnosed with low rectal adenocarcinoma were recruited to evaluate for LAPR surgical outcome performed at the $\mathrm{K}$ Hospital in Vietnam. The goal of the study was to compare post-surgical data from K Hospital with Western countries. Data were collected including age, gender, history of previous abdominal surgery, operative time, estimated blood loss (EBL), conversion rate, number of harvested lymph nodes, complications, time to return of bowel function (TRBF), length of stay (LOS), TNM staging and overall survival. Results: There were 69 male and 66 female patients. The mean age at diagnosis was 55.3 years (range 29 - 68 years). 19 patients had previous abdominal surgeries. One patient had a conversion to open LAPR due to ureteral and bladder injury. The mean and standard deviation for number of harvested lymph nodes was $14.6 \pm 5.3$; mean operative time $133 \pm 20.9$ minutes and mean EBL $13.6 \pm 12.2 \mathrm{ml}$. There were two cases of urinary retention that required bladder catheterization for more than 48 hours. There was no perioperative mortality. The TRBF was $33 \pm 4.4$ hours. Mean LOS was $7.4 \pm 1.8$ days. 98 patients (72.6\%) had stage II and 37 patients (27.4\%) had stage III disease. The overall 1-year, 2-year and 3-year survival was $95.8 \%, 82.1 \%$ and $73.3 \%$, respectively. Conclusion: LAPR for low rectal cancer in $\mathrm{K}$ hospital is feasible and safe.
\end{abstract}

\section{Subject Areas}

Gastroenterology \& Hepatology, Oncology 


\section{Keywords}

Laparoscopy, Abdominoperineal Resection, Rectal Cancer, National Cancer Hospital of Vietnam

\section{Introduction}

Rectal cancer is common, accounting for approximately one third of colorectal cancers. Surgery plays the most important role in treating rectal cancer.

Opened abdominoperineal resection (APR) was first performed by Ernest Miles in 1907 and has remained the gold standard for patients with operable low rectal cancer. It was not until 1991 when Jacobs introduced laparoscopic colectomy, which ushered in the era of laparoscopic colectomy [1] [2] [3]. After 20 years of development, laparoscopic colectomy is now accepted worldwide as an option for patients with colorectal cancer. Its advantages include less postoperative pain, shortened duration of postoperative ileus, faster recovery, shortened hospital stay and comparable oncologic outcomes [1] [4] [5] [6] [7].

Additional benefits of laparoscopic abdominoperineal resection (LAPR) include improved cosmetic outcomes from the smaller incision sites, as well as increased likelihood of genitourinary nerve preservation during total mesorectal excision (TME) due to the magnified view and thus improved visualization of the deep pelvic structures. All of these have lead to improved postoperative recovery and quality of life [1] [4]-[10].

These robust results, however, were mainly reported from institutions from the West and/or developed nations. The number of LAPR studies is limited in developing nations, such as Vietnam [11].

Vietnam is a developing nation that has a population of 90 million people [12] [13]. In this study, we report our experience with LAPR at the National Cancer Hospital of Vietnam, the largest cancer center, also known as K Hospital. We have performed LAPR since 2006 with about 50 cases per year. Despite limitations of facilities and human resources faced by developing nations such as Vietnam, we hypothesize LAPR can be performed safely and results can be comparable with those in developed nations.

\section{Materials and Methods}

Between January 2012 and December 2015, 135 patients diagnosed with adenocarcinoma of the low rectal cancer within $5 \mathrm{~cm}$ by digital rectal examination from the anal verge at $\mathrm{K}$ hospital were enrolled into the study to be performed LAPR. We excluded the following patients: tumor located $>5 \mathrm{~cm}$ from the anal verge or with tumor invading to the adjacent organs on image diagnosis, patients presented with recurrent disease, patients with evidence of distant disease, patients with serious comorbidity, patients who did not sign consent form, patients with intestinal obstruction or perforation, and general contraindications to 
laparoscopy. All patients underwent a complete history and physical examination. Preoperative workup included a colonoscopy, abdominal and pelvic CT scans and/or pelvic MRI, and/or endoscopic ultrasound, chest X.ray. Neoadjuvant chemoradiation would be offered to those with pretreatment clinical staging of $\mathrm{T} 4$ disease.

All patients provided written informed consent to the study. The study was approved by IRB of K Hospital.

Regarding operative techniques, we used 4 - 5 trocars. A subumbilical 10-mm trocar for the camera, a right paraumbilical $5-\mathrm{mm}$ trocar, and a $5 \mathrm{~mm}$ right \& left iliac fossa and suprapubic sites. The number and sites of ports may vary among surgeons due to surgeons' preference. The goal is to achieve the best visualization as possible.

Data collected and analyzed included age, gender, history of previous abdominal surgery, operation time as measured from the time of trocar placement to the completion of the last skin stitch, estimated blood loss (EBL) in ml, conversion rate, number of harvested lymph nodes, perioperative complications, time to significant flatus in the colostomy bag, length of postoperative hospital stay, and TNM stage. All patients were followed up regularly at 3 month intervals in the first 2 years and then every 6 months. Survival and recurrence were analyzed with the Kaplan-Meier method.

\section{Results}

There were 69 males (51\%) and 66 females (49\%). The mean age at diagnosis was 55.3 years (range 29 - 68 years, Table 1 ). Nineteen patients (14.1\%) had previous abdominal $(\mathrm{N}=5)$ or pelvic $(\mathrm{N}=14)$ surgeries.

Results of colonoscopy showed that the distance from the tumor to the anus was 1 to $3 \mathrm{~cm}$ in 130 (96\%) of patients. 133 patients (98.5\%) had tumors that involved more than half of the circumference. Magnetic resonance imaging (MRI) revealed serosal invasion by the tumors in all but one of the patients. No one received neoadjuvant therapy. Lymph nodal involvement defined by results of surgery was present in 37 patients (27.4\%). The histopathology results reported that 135 patients (100\%) tumors were invasive, 131 (97\%) tumors were 1 to $3 \mathrm{~cm}$ distant from the anus, tumor size was from 2 to $5 \mathrm{~cm}$ in 129 (95.6\%); serosa invasive tumors accounted for 78 (58\%), and T4 stage is 57 (42\%). Moderately differentiated adenocarcinoma was reported in 83 patients (61.5\%), 25 patients had well differentiated carcinoma and poorly differentiated carcinoma was reported in 27 patients.

Table 2 shows the surgical and postoperative data for the entire group. The average duration of surgery was $133 \pm 20.9$ minutes and the mean blood loss was $13.6 \pm 12.2 \mathrm{ml}$. The median number of harvested lymph nodes was $15( \pm 5.3)$. There was one patient who required conversion to an open APR, giving us a conversion rate of $0.8 \%$. This patient had ureteral injury so that he was converted for its reconstruction. Note that of the 19 patients who had previous ab- 
Table 1. Socio-demographic characteristics of the patients.

\begin{tabular}{cc}
\hline Variable & \\
\hline Gender & $69(51 \%)$ \\
Males & $66(49 \%)$ \\
Female & \\
Age & $55.3(29-68)$ \\
Mean (SD) & \\
History of previous abdominal surgery & $19(14 \%)$ \\
Yes & $116(86 \%)$ \\
No & \\
\hline
\end{tabular}

Table 2. Surgical and postoperative data.

\begin{tabular}{cccc}
\hline Variable & Our study & Simon [17] & Wai Lun Law [33] \\
\hline $\begin{array}{c}\text { Duration of surgery (min) } \\
\text { Mean (SD) }\end{array}$ & $133( \pm 20.9)$ & $213.5 \pm 46.2$ & $200(160-230)$ \\
Average blood loss (ml) & & & \\
Mean (SD) & $13.6( \pm 12.2)$ & $321.7(0-3000)$ & $200(100-400)$ \\
Harvested lymph nodes & & & \\
$\quad$ Mean (range) & $14.6( \pm 5.3)$ & $2.4 \pm 6.7$ & \\
$\begin{array}{c}\text { Conversion rate to open surgery } \\
\text { Number of patients (percent) }\end{array}$ & $1(0.8 \%)$ & & $7(5-10)$ \\
$\begin{array}{c}\text { Duration of hospitalization (days) } \\
\text { Mean (range) }\end{array}$ & $7.4(6-19)$ & $10.8(5-27)$ & \\
$\begin{array}{c}\text { Time to return of bowel function (hours) } \\
\text { Mean (SD) }\end{array}$ & $33.1( \pm 4.4)$ & $4.3(1-22)$ & \\
$\begin{array}{c}\text { Postoperative complications } \\
\text { Number of patients (percent) } \\
\text { Urinary retention }\end{array}$ & $2(1.5 \%)$ & & \\
Number of patients (percent) & $2(1.5 \%)$ & & \\
\hline
\end{tabular}

dominal surgeries, none required conversion. The mean duration of hospitalization was 7.4 (range: 6 - 19) days. The time to return of bowel function was $33.1 \pm$ 4.4 hours. There were two patients (1.5\%) who had postoperative complications. The complications were postoperative bowel obstructions. Their length of hospital stay was 7.4 days for each.

We had two cases of urinary retention $(1.5 \%)$ that required bladder catheterization for more than 48 hours.

Of our 135 patients, 98 (72.6\%) had stage II and 37 (27.4\%) had stage III disease: $78(57.8 \%)$ were stage IIA and $20(14.8 \%)$ patients had stage IIB. After a mean follow-up of 36 months, the overall 1-year, 2-year and 3-year survival was $95.8 \%, 82.1 \%$ and $73.3 \%$, respectively (Figure 1 ).

\section{Discussion}

In our series of 135 cases of laparoscopic abdominoperineal resection (LAPR), 




Figure 1. Overall survival of 135 patients.

the proportion of women and men were $49 \%$ and $51 \%$, respectively. These proportions are comparable to other series reported from Vietnam [11]. Similar to these authors, we excluded those patients who were older than 80 years of age out of concern for cardiopulmonary complications from abdominal $\mathrm{CO}_{2}$ insufflation [1].

The surgical outcomes in this patient series were satisfactory. We recommend that LAPR be offered to patients whose tumors are located less than $5 \mathrm{~cm}$ from the anal verge, had no invasion to adjacent organs $(\leq \mathrm{T} 3)$, and those who do not present with either bowel obstruction and/or peritonitis [1] [4] [5] [14] [15].

Our patients were staged preoperatively with clinical examination, abdominal and pelvic CT, pelvic MRI, and abdominal and pelvic ultrasound to evaluate tumor size, local invasion, regional lymph nodes and distal metastases.

A number of authors described dividing the sigmoid colon and rectum with an endolinear stapler before mobilizing the rectum [16] [17] [18]. We did not choose this method in order to reduce the expense associated with using the stapler. Instead of intracorporal division of the sigmoid colon and rectum, we chose to mobilize the sigmoid colon proximally to the descending colon and then mobilize the rectum down to the level of the levator muscle, following the ligation and division of the superior rectal artery. The rectum is then extruded through the perineal wound and divided extracorporeally.

Total mesorectal excision (TME) was first described by Heal in 1987, and has become widely accepted among colorectal surgeons as it reduces the risk of local recurrence [17]. Laparoscopic surgery is known to have advantages in the performance of TME. Its magnified visualization helps the surgeons to recognize and preserve the genitourinary nerve branches [17] [18] [19] [20] [21].

Lymph node metastasis is an important adverse prognostic factor in rectal cancer. Therefore adequate regional lymph node dissection is necessary to properly stage the patient. In our series, the average lymph node harvest was 14.6 which is comparable to Maschuw K et al. with 15 lymph nodes [22]. 
Performing an LAPR must be done carefully to avoid hemorrhage and achieve an adequate lymph node harvest. Therefore the operation time often is longer than for an open procedure. Simon et al. reported his operative time to be 213.5 minutes in a series of 99 patients [17]. Chung et al. reviewed LAR studies from 1991 to 2002, which contained 2890 patients, and found that the average operative time was 190 minutes [23]. Vietnamese authors have reported the operative time to be between 160 to 212 minutes [11] [24]. The surgeon's experience is an important determinant of the operative time; as expected, more experienced surgeons have shorter operative time [2]. Our time was 133 minutes $( \pm 20.9)$.

The classic open abdominoperineal resection is associated with intraoperative complications such as presacral haemorrhage, ureteral and bladder injury [1] [20] [24] [25] [26] [27] [28]. We had no case of presacral haemorrhage and only one case of left ureteral injury, which required conversion to an open surgery. This patient subsequently had a normal postoperative recovery. Our results suggest the superiority of laparoscopic TME over open surgery, based on historic data. It allowed clearer visualization of the anatomical structures in the deep pelvis and therefore allowed a more thorough dissection.

Many authors have described genitourinary (GU) function in patients undergoing abdominoperineal resection. They report that the GU function is better in the laparoscopic group than in the open group [20]. We had two cases of urinary retention $(1.5 \%)$ that required bladder catheterization for more than 48 hours. Other authors have reported that up to $17 \%$ of patients may require prolonged urinary catheterization [11] [17].

In this report, we did not assess the postoperative sexual function of our patients.

There are two general reasons for conversion to an open procedure. The first is technical, which includes uncontrolled hemorrhage from presacral bleeding, bladder and ureteral injury, small bowel injury, or adhesions which are not amenable for lysis. The second is the presence of a large locally invasive tumor that is not amenable for laparoscopic resection [1] [14] [15].

In our series of 135 patients, 19 patients (14.1\%) had previous abdominal surgery. However, all patients were successfully operated laparoscopically. Abraham et al. reviewed studies, which contained more than 6438 patients of LAR and reported a conversion rate of $7.7 \%$ [4]. Shek et al. reported a conversion rate of $4 \%$ in his series of 99 patients [29]. Lam et al. reported a zero conversion rate in his series of 45 patients [29].

Laparoscopic surgery minimizes abdominal organ trauma, leading to a reduction in postoperative pain. In addition, LAPR avoids laparotomy which is painful. As result, recovery time is shorter which shortens the postoperative hospital stay [9] [30] [31] [32].

In our series, parenteral analgesic injection was needed only within the first postoperative 48 hours. The average time to first passage of flatus was 33.1 hours $( \pm 4.4)$ and the average hospital stay was 7.4 days. These data are comparable to Trieu D [11]. Two cases in our series developed postoperative bowel obstruction 
requiring reoperation. The reason was a jejunal herniation through the perineal suture line, likely due to us performing interrupted suture closure. We have since performed continuous suturing of the perineal wound and have not since seen this complication.

Although laparoscopic colorectal cancer surgery has been practiced for two decades, the oncologic outcomes have been questioned until recently. Concerns for adequate oncologic dissection, adequate number of lymph nodes retrieved, and rate of recurrent disease were recently addressed by a number of multicenter controlled randomized studies, which demonstrated comparable results to the open technique in terms of specimen size, margin, lymph node harvest, complication rate, recurrence rate and overall survival rate [1] [4] [5] [16] [23].

After finishing treatment, these patients were followed by CEA every 3 months, repeat colonoscopy one year after diagnosis, CT chest and abdomen annually and physical exam and history every 3 months. Present studies [1] [4] [5] [6] [7] show that the oncologic results of both open and laparoscopic groups were comparable. In this study, long-term oncological outcome was analyzed. Cumulative 3-year overall survival was 73.3\%. Wai Lun Law reported 3-year overall survival of $80.9 \%$ [33]. However a larger sample size is needed to fully assess oncological outcomes.

\section{Conclusion}

Our initial results with 135 patients who underwent an LAPR at K Hospital, a National Cancer Hospital of Vietnam, are satisfactory. We demonstrated a low conversion rate and complication rate, adequate number of lymph node harvested, early return of bowel function, negligible blood loss, and short hospital stay. However, a larger series and longer follow-up are needed to evaluate the long-term oncologic impact.

\section{References}

[1] Bittner, R. (2006) Laparoscopic Surgery: 15 Years after Clinical Introduction. World Journal of Surgery, 30, 1190-1203. https://doi.org/10.1007/s00268-005-0644-2

[2] Leong, S., Cahill, R., Mehigan, B. and Stephens, R. (2007) Considerations on the Learning curve for Laparoscopic Colorectal Surgery: A View from the Bottom. The International Journal of Colorectal Disease, 22, 1109-1115. https://doi.org/10.1007/s00384-007-0302-2

[3] Malcolm, J. and Rieger, N. (2003) Audit and the Birth of the Abdomino-Perineal Excision for Carcinoma of the Rectum. ANZ Journal of Surgery, 73, 858-861. https://doi.org/10.1046/j.1445-2197.2003.02786.x

[4] Abraham, N., Byrne, C., Young, J. and Solomon, M. (2007) Meta-Analysis of Non-Randomized Comparative Studies of the Short-Term Outcomes of Laparoscopic Resection for Colorectal Cancer. ANZ Journal of Surgery, 77, 508-516. https://doi.org/10.1111/j.1445-2197.2007.04141.x

[5] Omer, A., Constantinides, V., Tekkis, P., Athanasiou, T., Purkayastha, S., Paraskevas, P., et al. (2006) Laparoscopic versus Open Surgery for Rectal Cancer: A Metal-Analysis. Annals of Surgical Oncology, 13, 413-424. 
https://doi.org/10.1245/ASO.2006.05.045

[6] Paun, B., Cassie, S., MacLean, A., Dixon, E. and Buie, W. (2010) Postoperative Complications Following Surgery for Rectal Cancer. Annals of Surgery, 251, 807-818. https://doi.org/10.1097/SLA.0b013e3181dae4ed

[7] Nelson, H., Sargent, D., Wieand, S., Fleshman, J., Anvari, M., Stryker, S., Beart, R., et al. (2004) A Comparison of Laparoscopically Assisted and Open Colectomy for Colon Cancer. The New England Journal of Medicine, 350, 2050-2059. https://doi.org/10.1056/NEJMoa032651

[8] Row, D. and Weiser, M. (2010) An Update on Laparoscopic Resection for Rectal Cancer. Cancer Control, 17, 16-24. https://doi.org/10.1177/107327481001700103

[9] Schwenk, W., Jacobi, C., Mansmann, U., Bohm, B. and Mulle, J. (2000) Inflammatory Response after Laparoscopic and Conventional Colorectal Resection-Results of a Prospective Randomized Trial. Langenbeck's Archives of Surgery, 385, 2-9. https://doi.org/10.1007/s004230050002

[10] Lee, S., Sonoda, T. and Milsom, J. (2007) Expediting of Laparoscopic Rectal Dissection Using a Hand-Access Device. Diseases of the Colon \& Rectum, 50, 927-929. https://doi.org/10.1007/s10350-007-0239-0

[11] Trieu, D., Đang, D. and Đo, T. (2006) Result of Total Mesorectal Excision and Conservation of Pelvic Autonomic Nerve in Treatment of Lower Third Rectal Cancer. Journal of Viet Nam Medicine, 319, 93-99.

[12] General Statistics Office of Vietnam. http://www.gso.gov.vn/default_en.aspx

[13] General Statistics Office of Vietnam. http://www.gso.gov.vn/default_en.aspx?tabid=508\&ItemID=10853

[14] Nguyen, D. (2007) Diagnosis and Treatment of Cancer Disease. Viet Nam Medical Publishing House, 5.

[15] Braga, M., Vignali, A., Gianotti, L., Zuliani, W., Radaelli, G., Gruarin, P., et al. (2002) Laparoscopic versus Open Colorectal Surgery: A Randomized Trial on Short-Term Outcome. Lippicott Williams et Wilkins, 236, 759-767. https://doi.org/10.1097/00000658-200212000-00008

[16] Slim, K. (2007) Laparoscopic Colorectal Surgery, Anything New? ANZ Journal of Surgery, 77, 519-520.

[17] Ng, S., Leung, K., Lee, J., Yiu, R., Li, J., Teoh, A., et al. (2006) Laparoscopic-Assisted versus Open Abdominoperineal Resection for Low Rectal, Cancer: A Prospective Randomized Trial. Annals of Surgical Oncology.

[18] Van Deurzen, D., Mannaerts, G. and Lange, J. (2006) Technique for Instant Stapling of the Sigmoid Mesentery and Mesorectum in Laparoscopic Colorectal Surgery. Surgical Endoscopy, 20, 1778-1779. https://doi.org/10.1007/s00464-005-0630-7

[19] Tiret, E. (1988) Total Mesorectal Excision and Preservation of Autonomous Genital Urinary Innervation in Rectal Cancer Surgery. EMC, 40-610.

[20] Quah, H., Jayne, D., Eu, K. and Seow-Choen, F. (2002) Bladder and Sexual Dysfunction Following Laparoscopically Assisted and Conventional Open Mesorectal Resection for Cancer. BJS, 89, 1551-1556. https://doi.org/10.1046/j.1365-2168.2002.02275.x

[21] Perez, R., Habr-Gama, A., Arazawa, S., Rawet, V., Siqueira, S., Kiss, D., et al. (2005) Lymph Node Micrometastasis in Stage II Distal Rectal Cancer Following Neoadjuvant Chemoradiation Therapy. International Journal of Colorectal Disease, 20, 434-439. https://doi.org/10.1007/s00384-004-0712-3

[22] Maschuw, K., Kress, R., Ramaswamy, A., Braun, I., Langer, P. and Gerdes, B. (2006) 
Short-Term Preoperative Radiotherapy in Rectal Cancer Patients Leads to a Reduction of the Detectable Number of Lymph Nodes in Resection Specimens. Langenbeck's Archives of Surgery, 391, 364-368.

https://doi.org/10.1007/s00423-006-0056-2

[23] De La Fuente, S., Manson, R., Ludwig, K. and Mantyh, C. (2009) Neoadjuvant Chemoradiation for Rectal Cancer Reduces Lymph Node Harvest in Proctectomy Specimens. Journal of Gastrointestinal Surgery, 13, 269-274. https://doi.org/10.1007/s11605-008-0717-2

[24] Nguyen, B., Nguyen, T., Do, D., Tu, H. and Le, T. (2006) Laparoscopic Total Mesorectal Excision in the Treatment of Lower Third Rectal Cancer. Journal of Viet Nam Medicine, 319, 131-138.

[25] Chung, C., Tsang, W., Kwok, S. and Li, M. (2003) Laparoscopy and Its Current Role in the Management of Colorectal Disease. Blackwell Publishing Ltd. Colorectal Disease, Vol. 5, 528-543. https://doi.org/10.1046/j.1463-1318.2003.00545.x

[26] Chengyu, L., Xiaoxin, J., Jian, Z., Chen, G. and Qi, Y. (2006) The Anatomical Significance and Techniques of Laparoscopic Rectal Surgery. Surgical Endoscopy, 20, 734-736. https://doi.org/10.1007/s00464-004-2247-7

[27] De Calan, L., Gayet, B., Bourlier, P. and Perniceni, T. (2004) Rectal Cancer: Surgical Anatomy, Preparation for Operation, and Patient Preparation. EMC, 40-606.

[28] De Calan, L., Gayet, B., Bourlier, P. and Perniceni, T. (2004) Surgery of Rectal Cancer: Laparotomy and Laparoscopy. EMC, 40-630.

[29] Kwok, S., Chung, C., Tsang, W., Chan, E. and Li, M. (2004) Laparoscopic Resection for Rectal Cancer in Patients with Previous Abdominal Surgery: A Comparative Study. Annals of the College of Surgeons Hong Kong, 8, 115-119. https://doi.org/10.1111/j.1442-2034.2004.00219.x

[30] Lam, T., Nguyen, H., Vo, L., Phung, C. and Tran, T. (2006) Early Outcomes of Laparoscopic Abdominoperineal Resection for Rectal Cancer. Journal of Ho Chi Minh City Medicine, 10, 190-195.

[31] Tang, C., Eu, K., Tai, B., Soh, J., MacHin, D. and Seow-Choen, F. (2001) Randomized Clinical Trial of the Effect of Open versus Laparoscopically Assisted Colectomy on Systemic Immunity in Patients with Colorectal Cancer. BJS, 88, 801-807. https://doi.org/10.1046/j.1365-2168.2001.01781.x

[32] Gao, F., Cao, Y. and Chen, L. (2006) Meta-Analysis of Short Term Outcomes after Laparoscopic Resection for Rectal Cancer. International Journal of Colorectal Disease, 21, 652-656. https://doi.org/10.1007/s00384-005-0079-0

[33] Law, W.L., Poon, J.T., Fan, J.K. and Lo, S.H. (2009) Comparison of Outcome of Open and Laparoscopic Resection for Stage II and Stage III Rectal Cancer. Annals of Surgical Oncology, 16, 1488-1493. https://doi.org/10.1245/s10434-009-0418-4 
Submit or recommend next manuscript to OALib Journal and we will provide best service for you:

- Publication frequency: Monthly

- 9 subject areas of science, technology and medicine

- Fair and rigorous peer-review system

- Fast publication process

- Article promotion in various social networking sites (LinkedIn, Facebook, Twitter, etc.)

- Maximum dissemination of your research work

Submit Your Paper Online: Click Here to Submit

Or Contact service@oalib.com 